\author{
국내 낙농가의 초유관리와 이용 \\ 정석근*·함준상*·김동훈*·채현석*·유영모*·장애라*·권일경**・이승규* \\ 농촌진흥청 국립축산과학원*, 강원대학교**
}

\title{
Colostrum Management and Use in Domestic Dairy Farms
}

\author{
Seok-Geun Jeong*, Jun-Sang Ham*, Dong-Hun Kim*, Hyun-Seok Chae*, Young-Mo You*, Aera Jang*, Il-Kyung Kwon** \\ and Seung-Gyu Lee* \\ National Institute of Animal Science, RDA*, Kangwon National University**
}

\begin{abstract}
Colostrum provide a complete diet for the newborn calves. In ruminants, colostrum is also the sole source of initial acquired immunity for the offspring. Colostrum, therefore, plays an important role in ruminants host defense. Bovine colostrum imparts passive immunity to newborn calves during the first $24 \mathrm{~h}$ of life and generally has been fed for the first 3 days after birth. Colostrum can be preserved conveniently for future use by brief refrigeration, freezing, or storage at ambient temperatures (fermentation or chemical treatment). Colostrum management were surveyed via data collection from 67 dairy farms in Gyeonggi and Chungnam provinces. After parturition for five days the total amount of produced colostrum was $80.4 \mathrm{~kg}$ on average, and the average amount of lactation fed to a calf was $20.9 \mathrm{~kg}$. According to the survey results, identified treatment methods for surplus colostrum are as follows; disposal $17.9 \%$, other calf feeding $37.3 \%$, storage $22.4 \%$, other livestock feeding $20.9 \%$ and other treatment $1.5 \%$. For improvement in the quality of colostrum, there must be controlled usage of medicines (such as antibiotics) before and after parturition, proper choices of milk-drying agents, and increased milking yields during the early stage of the milking period.
\end{abstract}

(Key words : Colostrum, Calf, Dairy farm, Colostrum management)

\section{I. 서 론}

포유동물은 분만과 동시에 자축의 원활한 성장을 위하 여 1 주일 정도 초유를 분비하게 되는데, 초유 중에는 다 양한 생리활성물질이 함유되어 있어 신생 자축의 생리기 능을 원활히 해준다(Butler, 1971, 1986). 신생 송아지는 신 선한 어미의 초유를 직접 포유하거나 다른 방법으로 2 3 일간 먹게 된다. Huber(1974)는 대부분의 건강한 젖소는 포유기간 동안 송아지에게 급여하는데 필요한 양보다 훨 씬 많은 양의 초유를 생산하고, 평균 초유 생산량은 초산 우가 $32.7 \mathrm{~kg}$, 경산우가 $41.7 \mathrm{~kg}$ 이라 보고하였다. 통계청 '가축통계' 자료 (http://www.dairy.or.kr/)에 의하면 국내 젖 소 사육두수는 2008년 6월 445,213두를 사육하고 있으며, 사육농가는 7,219호로 호당 평균 사육두수는 62 두로 2005 년 6 월 호당 53 두에 비해 약 $12 \%$ 로 증가하여 젖소사육의 전업화가 꾸준히 진행되고 있다. 따라서 호당 생산되는 잉여의 초유도 증가하고 있는 실정이다. 초유는 원료유로 적합하지 않아 현재 국내에서는 분만 후 5 일 이내에 생산
된 초유는 납유를 금지하고 있다. 그러나 이런 단점 외에 초유에는 태아가 성장하는데 필요한 에너지와 영양소를 함유하고 있으며, 미량의 성장인자와 감염으로 자축을 보 호할 수 있는 immunoglobulin $(\mathrm{Ig})$ 과 같은 면역 단백질도 함유하고 있다 (Hadorn 등, 1997). 현재 농가에서 납유하지 못하는 다량의 초유에 대하여 그 생리적 기능과 이용방법 에 대한 관심이 부족하여 초유를 효율적으로 이용하고 관 리하는 체계가 마련되어 있지 않다. 선진 낙농국에서는 초유의 생리적 기능과 중요성에 대한 인식이 높아져 초유 에 대한 연구가 활발히 진행되고 있으며, 초유로부터 유 용성분의 분리정제를 비롯하여 다양한 이용기술의 개발과 이와 관련된 산업이 활성화되고 있다. 본 연구는 잉여초 유를 이용한 제품연구와 개발에 앞서 국내 낙농가에서 초 유의 생산과 이용에 대한 관리실태를 조사 분석하고, 실 제로 이용할 수 있는 초유의 생산량 추정과 잉여 초유에 대한 적절한 이용방법을 모색하기 위한 기초 자료를 제공 하기 위한 것이다.

Corresponding author : Seung-Gyu Lee, Quality Control and Utilization of Animal Products Division, National Institute of Animal Science, RDA, Suwon 441-706

Tel: +82-31-290-1696, Fax:: +82-31-290-1697, E-mail: 1sgyu007@rda.go.kr 


\section{ㅍ. 재료 및 방법}

\section{1. 설문조사 지역 및 방법}

설문조사지역은 낙농가가 많이 분포한 경기지역과 충남 지역을 중심으로 조사하였으며, 조사 농가 수는 67농가로 지역별 분포는 경기지역 36 농가, 충남지역 27 농가와 기타 지역 4농가를 조사하였다. 낙농가의 초유관리 및 이용실 태 조사는 설문지 양식에 의거하여 농가를 방문하여 설문 조사를 실시하였다.

\section{2. 주요설문 조사 내용}

\section{(1) 일반현황}

농가일반현황, 사육규모, 원유품질, 납유현황

(2) 초유 착유 관리

송아지 초유급여 방법 및 급여량, 착유방법, 착유량, 송 아지 분리, 착유기 관리

\section{(3) 초유이용 실태}

초유급여기간, 초유 대처사항, 냉동초유, 납유 전 검사 의뢰 및 조치사항

(4) 건유 및 분만우 관리

건유기간, 건유연고 선발, 건유연고 사용회수, 항생제 사용 현황

(5) 초유활용 관리

초유가공, 잉여초유관리, 자원화 방안

\section{3. 통계처리}

본 시험에서 얻어진 성적은 SAS Package Program(1995)
을 이용하여 분산분석을 실시하였으며, 유의성은 $x^{2}$ 검정, T-test를 실시하였다.

\section{III. 결과 및 고찰}

\section{1. 일반현황}

국내 낙농가의 초유관리 및 이용실태 설문조사에 응답 한 농가의 일반사육 및 생산현황 조사결과는 Table 1과 같다. 조사농가의 평균 낙농경력은 $15.73 \pm 7.2$ 년 이었으며, 경기지역 (Gyunggi)이 충남지역 (Chungnam + Others)에 비해 낙농경력이 높은 것으로 나타났다. 평균 착유우 두수는 $28.6 \pm 15.9$ 두이었고, 건유우는 $6.0 \pm 4.7$ 두, 육성우 및 송아 지는 각각 $19.9 \pm 13.0$ 두와 $7.7 \pm 6.1$ 두로 총 사육 두수는 호 당 $61.4 \pm 34.3$ 두를 사육하고 있는 것으로 조사되었다. 충 남지역이 경기지역에 비해 사육두수가 유의적으로 많은 것으로 나타났다. 일일 납유량은 $726.3 \pm 446 \mathrm{~kg}$ 인 것으로 나타났으며, 충남지역이 경기지역에 비해 일일 납유량이 유의적으로 높았다. 경기지역이 기타지역을 포함한 충남 지역에 비해 사육두수 규모는 작은 것으로 나타났으나, 목장 경력은 다소 높은 것으로 나타났다. 전국 호당 사육 두수 38.6 두와 비교하여 조사 농가의 사육기반이 큰 것으 로 분석되었는데 이는 충남지역 낙농가의 사육두수가 타 지역에 비해 높았기 때문으로 분석되었다.

\section{2. 분만 후 송아지 관리 현황}

농가에서 분만 후 송아지 관리 실태와 초유의 착유 시 기별 관리실태를 Table 2에 나타내었다. 대부분의 농가에 서 분만 후 초유를 급여하는 시간은 1시간 이내가 $58.2 \%$, $1 \sim 2$ 시간 이내가 $26.9 \%, 3 \sim 6$ 시간 사이가 $10.4 \%, 6$ 시간 이 후가 $4.5 \%$ 로 나타났으며, 조사지역간의 차이는 없었으나 경기지역에서 6 시간 이후에 초유를 급여한다는 농가도 $8.3 \%$ 를 차지하는 것으로 조사되었다.

Table 1. Survey for current status of dairy farms in Gyunggi and Chungnam region

\begin{tabular}{|c|c|c|c|c|c|c|c|c|}
\hline \multirow[b]{2}{*}{ Region } & \multirow{2}{*}{$\begin{array}{c}\text { No. of } \\
\text { farm } \\
(\%) \\
\end{array}$} & \multirow{2}{*}{$\begin{array}{l}\text { Career } \\
\text { (year) }\end{array}$} & \multicolumn{5}{|c|}{ Raising herds(head) } & \multirow{2}{*}{$\begin{array}{c}\text { Milk } \\
\text { yield } \\
(\mathrm{kg} / \mathrm{d}) \\
\end{array}$} \\
\hline & & & $\begin{array}{c}\text { Milking } \\
\text { cows }\end{array}$ & $\begin{array}{l}\text { Drying off } \\
\text { cows }\end{array}$ & Heifers & Calves & Total & \\
\hline Gyunggi & $\begin{array}{c}36 \\
(53.7) \\
\end{array}$ & $17.25^{1)} \pm 7.6$ & $22.9 \pm 9.4$ & $4.7 \pm 2.9$ & $15.2 \pm 7.5$ & $5.9 \pm 4.0$ & $47.5 \pm 19.0$ & $585.8 \pm 302^{2)}$ \\
\hline Chungnam & $\begin{array}{c}31 \\
(46.3) \\
\end{array}$ & $13.97 \pm 6.5$ & $35.2 * \pm 19.2$ & $7.4 * \pm 5.8$ & $25.2 * \pm 15.7$ & $9.7 * \pm 7.4$ & $77.6^{*} \pm 40.7$ & $889.5 * * \pm 528$ \\
\hline Total & $\begin{array}{c}67 \\
(100.0) \\
\end{array}$ & $15.73 \pm 7.2$ & $28.6 \pm 15.9$ & $6.0 \pm 4.7$ & $19.9 \pm 13.0$ & $7.7 \pm 6.1$ & $61.4 \pm 34.3$ & $726.3 \pm 446$ \\
\hline
\end{tabular}

\footnotetext{
1) KDC : Korea Dairy Committee.

2) Mean \pm SD.

* : Significant at 5\% probability levels.

** : Significant at $1 \%$ probability levels.
} 
Table 2. Management of colostrum feeding and separation time of calf from dam

\begin{tabular}{|c|c|c|c|c|c|c|c|c|}
\hline \multirow{2}{*}{ Items } & \multicolumn{4}{|c|}{ Colostrum feeding time after calving } & \multicolumn{4}{|c|}{ Separation time from dam ${ }^{1)}$} \\
\hline & $\langle 1 \mathrm{~h}$ & $1 \sim 2 \mathrm{~h}$ & $3 \sim 6 \mathrm{~h}$ & $>6 \mathrm{~h}$ & IB & In $8 \mathrm{~h}$ & In $24 \mathrm{~h}$ & $\mathrm{RC}$ \\
\hline Gyunggi & 21 & 9 & 3 & 3 & 31 & 3 & 1 & 1 \\
\hline (No., \%) & $(58.3)$ & $(25.0)$ & $(8.3)$ & $(8.3)$ & $(86.1)$ & $(8.3)$ & $(2.8)$ & $(2.8)$ \\
\hline Chungnam & 18 & 9 & 4 & 0 & 28 & 3 & 0 & 0 \\
\hline (No., \%) & $(58.1)$ & $(29.0)$ & $(12.9)$ & $(0.0)$ & $(90.3)$ & $(9.7)$ & $(0.0)$ & $(0.0)$ \\
\hline Total, & 39 & 18 & 7 & 3 & 59 & 6 & 1 & 1 \\
\hline (No., \%) & $(58.2)$ & (26.9) & (10.4) & (4.5) & $(88.1)$ & (8.9) & (1.5) & (1.5) \\
\hline
\end{tabular}

1) IB : immediately after birth. RC : raising with cow.

분만 후 송아지 분리시기에 대해 조사한 결과 분만 즉 시가 $88.1 \%, 8$ 시간 이내가 $8.9 \%, 24$ 시간 이내에 어미와 함 께 합사한다가 각각 $1.5 \%$ 로 나타났으며, 조사지역간의 차 이는 없었다. Canada Alberta주의 농가조사 결과 보고를 보면 초유급여 시간이 4시간 이내가 $60.3 \%, 12$ 시간 이내 가 $36.7 \%, 24$ 시간 이내가 $1.6 \%$ 로, 24 시간 이후에 초유를 급여하는 농가가 $1.0 \%$ 이었다. 분만 후 송아지 분리시간 항목에서는 분만 즉시 분리한다가 $17.5 \%, 8$ 시간 이내에 분리한다가 $54.6 \%, 24$ 시간 이내에 분리한다가 $24.0 \%, 24$ 시 간 이후에 분리한다가 $3.9 \%$ 이었다는 보고와 유사한 것으 로 나타났다(Spicer 등, 1994). Weaver 등 (2000)은 초유 Ig 의 능동수송은 송아지의 건강을 위해 필수적이라고 하였 으며, 초유 섭취시간, 초유 급여방법과 급여량, 섭취된 초 유의 Ig 농도, 어미 소의 나이를 포함하는 많은 요인들이 초유 Ig 흡수에 영향을 미친다고 보고하였고, Geene (1986) 은 초유의 생산과 품질에 관한 연구를 통해 무감마글로블 린증 (agammaglobulinaemia)의 기간을 줄이기 위해 초유의 조기포유가 필수적이라 하였다. 본 연구조사 결과에서는 대부분의 농가에서 조기에 초유급여가 이루어지고 있는 것으로 나타났다.

\section{3. 초유 착유방법}

초유를 자원화하기 위하여 농가에서 생산되는 초유의 착유 방법과 착유량에 관하여 조사한 결과 Table 3 과 같
다. 농가에서 첫 초유 착유 방법 $(1,2$ 회 차)을 살펴보면, 손착유 농가가 $56.7 \%$ 를 차지하여 가장 많았으며, 다음은 착유기로 착유하는 농가가 $41.8 \%$, 송아지를 어미와 합사 시키는 농가가 $1.5 \%$ 로 조사되었다. 또한, 첫 초유 착유량 에 관해 조사한 결과 한번 급여할 만큼 $(2 \mathrm{~kg}$ 내외 $)$ 이 $41.8 \%$, 두세 번 급여할 만큼 $(4 \sim 6 \mathrm{~kg})$ 이 $40.3 \%$, 처음부터 모두 착유한다가 $16.4 \%$ 로 나타났다. 한번 급여할 만큼 착 유하는 농가는 충남지역이, 2 3회 급여할 만큼 착유하는 농가와 처음부터 모두 착유하는 농가는 경기지역이 많은 것으로 나타났으나, 통계적으로 유의적인 차이는 없었다.

착유기로 초유를 착유하는 시점은 초산우는 $3.0 \pm 2.0$ 회, 경산우는 $2.6 \pm 1.9$ 회부터인 것으로 조사되었으며, 경기지 역이 충남지역에 비해 늦게 착유기 착유를 실시하는 것으 로 나타났다. Pritchett 등 (1991)은 첫 초유 착유량은 평균 $8.5 \pm 4.8 \mathrm{~kg}$ 으로 매우 다양한 분포를 보이고 있다고 보고하 였는데, 국내의 첫 초유 착유량이 1 회 송아지 급여량 또 는 2 3회 급여할 만큼 착유하는 농가가 많은 본 조사결 과와는 차이가 있는 것으로 나타났다. 따라서 국내의 경 우 초유의 자원화를 활성화하기 위해서는 첫 초유의 착유 량 수준을 증가시켜야 할 것으로 분석되었다.

\section{4. 부분착유 이유 및 착유기 관리}

초유의 자원화를 유도하기 위해 분만 후 첫 초유 및 1 2회의 착유를 모두 착유하지 않고 일부분만 착유하는

Table 3. Milking methods and quantity of first milking

\begin{tabular}{|c|c|c|c|c|c|c|c|c|c|}
\hline \multirow{2}{*}{ Items } & \multicolumn{3}{|c|}{$\begin{array}{l}\text { Milking method of first } \\
\text { colostrum }\end{array}$} & \multicolumn{4}{|c|}{ Amount of first colostrum } & \multicolumn{2}{|c|}{$\begin{array}{c}\text { Times of milker milking } \\
\text { (times) }\end{array}$} \\
\hline & Hand & Milker & Suckling & $2 \mathrm{~kg}$ & $4 \sim 6 \mathrm{~kg}$ & All & Other & Primipara & Multipara \\
\hline $\begin{array}{l}\text { Gyunggi } \\
\text { (No., \%) }\end{array}$ & $\begin{array}{c}18 \\
(50.0)\end{array}$ & $\begin{array}{c}17 \\
(47.2)\end{array}$ & $\begin{array}{c}1 \\
(2.8) \\
\end{array}$ & $\begin{array}{c}11 \\
(30.6)\end{array}$ & $\begin{array}{c}16 \\
(44.4)\end{array}$ & $\begin{array}{c}8 \\
(22.2) \\
\end{array}$ & $\begin{array}{c}1 \\
(2.8) \\
\end{array}$ & $3.1 \pm 2.2^{1)}$ & $2.8 \pm 2.2$ \\
\hline $\begin{array}{c}\text { Chungnam } \\
\text { (No., \%) }\end{array}$ & $\begin{array}{c}20 \\
(64.5)\end{array}$ & $\begin{array}{c}11 \\
(35.5)\end{array}$ & $\begin{array}{c}0 \\
(0.0)\end{array}$ & $\begin{array}{c}16 \\
(51.6)\end{array}$ & $\begin{array}{c}12 \\
(38.7)\end{array}$ & $\begin{array}{c}3 \\
(9.7)\end{array}$ & $\begin{array}{c}0 \\
(0.0)\end{array}$ & $2.9 \pm 1.8$ & $2.4 \pm 1.5$ \\
\hline $\begin{array}{c}\text { Total, } \\
\text { (No,. \%) }\end{array}$ & $\begin{array}{c}38 \\
(56.7)\end{array}$ & $\begin{array}{c}28 \\
(41.8)\end{array}$ & $\begin{array}{c}1 \\
(1.5)\end{array}$ & $\begin{array}{c}27 \\
(40.3)\end{array}$ & $\begin{array}{c}28 \\
(41.8)\end{array}$ & $\begin{array}{c}11 \\
(16.4)\end{array}$ & $\begin{array}{c}1 \\
(1.5)\end{array}$ & $3.0 \pm 2.0$ & $2.6 \pm 1.9$ \\
\hline
\end{tabular}

\footnotetext{
1) Mean \pm SD.
} 
농가를 대상으로 첫 초유를 부분 착유하는 이유에 관한 조사결과와 초유의 품질향상을 위한 방안 도출을 위해 초 유를 착유한 착유기의 세척, 소독관리에 대한 조사결과를 Table 4에 나타내었다. 부분 착유를 하는 이유는 어미 소 의 건강을 위하여가 $45.8 \%$, 유열 예방을 위해서가 $47.5 \%$, 기타가 $6.7 \%$ 로 조사되어 대부분의 농가에서 어미 소의 건 강과 분만 후 어미 소의 유열 발생을 예방하기 위해 부분 착유를 하고 있는 것으로 나타났다. 또한 초유를 착유한 착유기의 세척관리에 대한 조사결과, 착유 후 매회 세척 과 소독을 실시한다가 $82.1 \%$, 매회 물로만 세척한다가 $14.9 \%, 2 \sim 3$ 일에 1회 세척 소독하는 등 기타 방법으로 세 척소독을 하는 농가가 $3.0 \%$ 를 차지하고 있는 것으로 조사 되었으며, 조사지역간의 차이는 없는 것으로 나타났다. 아 직도 많은 농가에서 초유를 착유한 착유기의 세척과 소독 관리가 소홀한 것으로 나타났으며, Stabel (2001)이 미국의 농장보고에서 보고한 바와 같이 $20 \sim 40 \%$ 의 우군이 요네병 수준이었다는 보고로 볼 때 초유의 미생물 오염예방을 위 하여 개선이 필요한 것으로 나타났다.

Pritchett 등 (1991)이 보고한 첫 초유의 생산량과 초유의 $\mathrm{IgG}$ 함량 간에는 높은 부의 상관관계 $(\mathrm{r}=-0.29)$ 가 있다고
하였으나, Stott 등 (1981)은 젖소 초유의 착유회수에 따른 $\mathrm{Ig}$ 함량의 변화를 조사한 결과 각 분방별로 $100 \mathrm{ml}$ 씩 착유 한 처리구, 완전 착유구의 초유 $\mathrm{IgG}$ 함량은 각각 63.2 와 $73.4 \mathrm{mg} / \mathrm{ml}, \mathrm{IgM}$ 은 12.4 와 $2.0 \mathrm{mg} / \mathrm{ml}, \mathrm{IgA}$ 는 16.7 과 $17.8 \mathrm{mg} /$ $\mathrm{ml}$ 로 차이가 없다고 하였다. Lori 등 (1991)이 보고한 초유 첫 착유량 평균 $8.5 \pm 4.8 \mathrm{~kg}$ 을 고려할 때 초유를 자원화하 기 위해서는 첫 초유 착유량의 적정 수준을 결정하여야 할 것으로 판단된다.

\section{5. 농가 초유 생산량 및 포유 이용량}

농가에서 납유 금지기간(분만 후 5일간)동안 생산된 초 유에 대한 이용성을 증진시키기 위하여 1 회부터 10 회까지 의 초유의 착유량과 송아지 초유 급여량에 대한 현황을 조사한 결과를 Table 5에 나타내었다. 첫 번째와 두 번째 착유는 대부분의 농가에서 $1 \sim 2$ 회 초유를 급여할 양만큼 을 착유하여 송아지에게 포유를 하고 있었다. 분만 후 5 일간의 초유 총 생산량은 두당 평균 $80.2 \mathrm{~kg}$ 이었으며, 송 아지에게 급여한 포유량은 평균 $20.9 \mathrm{~kg}$ 인 것으로 조사되 었다. 이상의 결과는 Huber(1974)가 초산우 및 경산우의

Table 4. Reasons of partial milking of colostrum and cleaning of milker

\begin{tabular}{|c|c|c|c|c|c|c|}
\hline \multirow{2}{*}{ Items } & \multicolumn{3}{|c|}{ Reason of partly milking of colostrum ${ }^{1)}$} & \multicolumn{3}{|c|}{ Cleaning of milker ${ }^{2}$} \\
\hline & $\mathrm{DH}$ & PMF & Other & WC & $\mathrm{CD}$ & Other \\
\hline $\begin{array}{l}\text { Gyunggi } \\
\text { (No., \%) }\end{array}$ & $\begin{array}{c}11 \\
(35.5)\end{array}$ & $\begin{array}{c}17 \\
(54.8) \\
\end{array}$ & $\begin{array}{c}3 \\
(7.7) \\
\end{array}$ & $\begin{array}{c}4 \\
(11.1)\end{array}$ & $\begin{array}{c}31 \\
(86.1)\end{array}$ & $\begin{array}{c}1 \\
(2.8) \\
\end{array}$ \\
\hline $\begin{array}{l}\text { Chungnam } \\
\text { (No., \%) }\end{array}$ & $\begin{array}{c}16 \\
(57.1)\end{array}$ & $\begin{array}{c}11 \\
(39.3)\end{array}$ & $\begin{array}{c}1 \\
(3.6)\end{array}$ & $\begin{array}{c}6 \\
(19.4)\end{array}$ & $\begin{array}{c}24 \\
(77.4)\end{array}$ & $\begin{array}{c}1 \\
(3.2) \\
\end{array}$ \\
\hline $\begin{array}{c}\text { Total, } \\
\text { (No., \%) }\end{array}$ & $\begin{array}{c}27 \\
(45.8)\end{array}$ & $\begin{array}{c}28 \\
(47.5)\end{array}$ & $\begin{array}{c}4 \\
(6.7)\end{array}$ & $\begin{array}{c}10 \\
(14.9)\end{array}$ & $\begin{array}{c}55 \\
(82.1)\end{array}$ & $\begin{array}{c}2 \\
(3.0)\end{array}$ \\
\hline
\end{tabular}

1) $\mathrm{DH}$ : for dam's health, PMF : prevent milk fever.

2) $\mathrm{WC}$ : water clean everytime, $\mathrm{CD}$ : clean and detergent everytime.

Table 5. Milking and feeding quantity by milking times

(Unit : kg)

\begin{tabular}{|c|c|c|c|c|c|c|c|c|c|}
\hline \multirow{2}{*}{ Region } & \multirow{2}{*}{ Quantity } & \multicolumn{8}{|c|}{ No. of milking and feeding } \\
\hline & & 1 & 2 & 3 & 4 & $5 \sim 6$ & $7 \sim 8$ & $9 \sim 10$ & Total \\
\hline \multirow{3}{*}{ Gyunggi } & Milking & $4.3 \pm 3.2^{2)}$ & $6.1 \pm 3.6$ & $7.8 \pm 3.1$ & $8.7 \pm 3.5$ & $16.1 \pm 4.3$ & $18.4 \pm 4.4$ & $20.7 \pm 4.3$ & 82.1 \\
\hline & Feeding & $1.8 \pm 0.4$ & $2.1 \pm 0.4$ & $2.1 \pm 0.6$ & $2.2 \pm 0.6$ & $4.3 \pm 0.9$ & $4.3 \pm 0.9$ & $4.3 \pm 0.9$ & 21.1 \\
\hline & Residue $^{1)}$ & $2.3 \pm 2.8$ & $3.9 \pm 3.2$ & $5.3 \pm 2.9$ & $7.2 \pm 3.4$ & $11.3 \pm 3.6$ & $14.3 \pm 4.3$ & $16.1 \pm 4.1$ & 60.4 \\
\hline \multirow{3}{*}{ Chungnam } & Milking & $3.3 \pm 1.7$ & $5.1 \pm 2.5$ & $6.9 \pm 2.7$ & $8.7 \pm 3.8$ & $15.4 \pm 4.6$ & $17.7 \pm 4.5$ & $19.0 \pm 4.7$ & 76.1 \\
\hline & Feeding & $2.4 \pm 3.3$ & $1.9 \pm 0.3$ & $2.0 \pm 0.5$ & $2.2 \pm 0.6$ & $4.1 \pm 0.8$ & $4.1 \pm 0.8$ & $4.2 \pm 0.8$ & 20.9 \\
\hline & Residue & $1.5 \pm 1.7$ & $3.3 \pm 2.5$ & $4.6 \pm 2.5$ & $6.7 \pm 3.8$ & $11.5 \pm 4.3$ & $13.6 \pm 4.4$ & $15.7 \pm 5.0$ & 56.9 \\
\hline \multirow{3}{*}{ Total } & Milking & $3.8 \pm 2.6$ & $5.7 \pm 3.2$ & $7.4 \pm 2.9$ & $9.2 \pm 3.6$ & $15.8 \pm 4.4$ & $18.1 \pm 4.4$ & $20.2 \pm 4.5$ & 80.2 \\
\hline & Feeding & $1.8 \pm 0.4$ & $2.0 \pm 0.5$ & $2.1 \pm 0.6$ & $2.2 \pm 0.6$ & $4.4 \pm 0.8$ & $4.2 \pm 0.8$ & $4.2 \pm 0.8$ & 20.9 \\
\hline & Residue & $1.9 \pm 2.4$ & $3.6 \pm 2.0$ & $5.0 \pm 2.8$ & $7.0 \pm 3.6$ & $11.4 \pm 3.9$ & $14.0 \pm 4.3$ & $16.0 \pm 4.5$ & 58.9 \\
\hline \multicolumn{2}{|c|}{ Aggregate of residue } & 1.9 & 5.5 & 10.6 & 17.5 & 28.9 & 42.9 & 58.6 & - \\
\hline
\end{tabular}


초유생산량이 각각 $32.7 \mathrm{~kg}$ 과 $41.7 \mathrm{~kg}$ 이었다는 보고와 $\mathrm{Yu}$ 등(1976)이 보고한 홀스타인 평균 초산우 생산량 $24 \mathrm{~kg}$ 과 경산우 $54 \mathrm{~kg}$ 이었다는 보고한 것 보다는 많았다. 또한 Drevjany 등(1975)이 보고한 평균 초유 생산량 $39 \sim 52 \mathrm{~kg}$ 보 다는 많은 양이었으며, 분만 후 3 일까지 평균 $60 \mathrm{~kg}$ 을 착 유하여 $15 \mathrm{~kg}$ 을 송아지에게 급여하였다는 Kirihara (1990)의 보고와는 비슷한 결과였다.

\section{6. 남는 초유처리 방법}

농가에서 남는 초유의 처리방법에 대한 조사결과는 Table 6 에 나타난 바와 같이 그낭 버린다가 $17.9 \%$, 다른 송아지 포유용으로 이용한다가 $37.3 \%$, 저장 이용한다가 $22.4 \%$, 다른 가축에게 준다가 $20.9 \%$, 기타방법으로 처리한 다가 $1.5 \%$ 로 조사되었으며 조사지역간의 차이는 나타나지 않았다. Stabel (2001)은 샘플의 20 40\%가 요네병 우군으로 조사되어 질병을 전파할 수 있는 미생물에 오염된 초유와 우유의 부적절한 폐기는 송아지에게 질병전파의 기회를 줄 수 있으므로 단순 폐기는 지양해야 된다고 보고하였다. 미국의 국가 육성우 평가 프로젝트에서 송아지의 초유급 여 실태와 초유 대용유의 이용형태에 관한 연구보고 (Heinrichs 등, 1995)에 따르면, 이유 전에 급여하는 액상 사료 원으로는 전유, 초유, 약물처리 대용유, 비 약물처리 대용유, 대용유, 유방염유, 항생제 우유 등이 이용되고 있 다고 하였다. 국내 농가의 경우 남는 초유를 송아지 포유
용과 저장 이용한다는 농가가 많았으며, 그낭 버린다는 농가가 많지 않은 것으로 조사되었으나, 질병전파와 환경 오염 등을 고려할 때 남는 초유의 폐기에도 관심을 가져 야 할 것으로 사료된다.

\section{7. 냉동초유의 이용현황}

초유를 냉동 보관하면서 초유를 이용하지 못할 경우 이용하는 초유의 품질을 알아보기 위하여 사용되는 초유 의 착유 횟수와 저장기간 및 보유량에 대한 내용을 조사 하여 그 결과를 Table 7에 나타내었다. 초유급여가 불가능 할 경우 냉동초유 이용농가는 $32.8 \%$ 이었으며, 냉동초유 를 이용하지 않는 농가가 $67.2 \%$ 로 월등히 많은 것으로 조 사되었다. 냉동초유를 이용하여 초유급여가 불가능한 경 우에 이용한다는 농가를 대상으로 냉동초유에 이용하는 초유의 착유 회수는 1 차 착유한 것만을 이용한다가 $27.3 \%, 1$ 2차 착유한 것을 이용한다가 $63.6 \%$ 로 가장 높게 나타났고, 1 4차 착유한 것을 이용한다가 $9.1 \%$ 로 나타나 대부분 1차 또는 1 2차 착유한 것을 이용하는 것으로 나 타나 냉동초유에 이용되는 초유는 적절한 것으로 조사되 었으며, 조사지역간의 차이는 나타나지 않았다. 낙농가에 서 냉동초유로 저장하고 있는 양은 약 $6.93 \pm 5.47 \mathrm{~kg}$ 으로 경기지역의 농가에서 다소 많이 보유하고 있었으며, 냉동 시킨 초유의 이용기간을 조사한 결과 3 개월 이내에 사용 한다가 $81.8 \%, 4 \sim 5$ 개월 이내에 사용한다가 $4.6 \%, 6$ 개월 이

Table 6. Utilization methods of surplus colostrum in the farms

\begin{tabular}{lccccc}
\hline \multirow{2}{*}{ Items } & \multicolumn{3}{c}{ Surplus colostrum utilization } \\
\cline { 2 - 6 } & Dispose & FC & SU & OL & Other \\
\hline \hline \multirow{2}{*}{ Gyunggi (No., \%) } & 5 & 13 & 8 & 9 & 1 \\
& $(13.9)$ & $(36.1)$ & $(22.2)$ & $(25.0)$ & $(2.8)$ \\
Chungnam (No., \%) & 7 & 12 & 7 & 5 & 0 \\
\hline \multirow{2}{*}{ Total (No., \%) } & $(22.6)$ & $(38.7)$ & $(22.6)$ & $16.1)$ & $(0.0)$ \\
\hline
\end{tabular}

1) FC : feeding for other calf, $\mathrm{SU}$ : storage and use, $\mathrm{OL}$ : feeding for other livestock.

Table 7. Utilization and using periods of frozen colostrum

\begin{tabular}{|c|c|c|c|c|c|c|c|c|c|}
\hline \multirow{2}{*}{ Items } & \multicolumn{4}{|c|}{ No. of milking for freezing colostrum(times) } & \multirow{2}{*}{$\begin{array}{l}\text { Quantity of } \\
\text { stored } \\
\text { colostrum } \\
(\mathrm{kg})\end{array}$} & \multicolumn{4}{|c|}{$\begin{array}{l}\text { Using period } \\
\text { (months) }\end{array}$} \\
\hline & 1 & $1 \sim 2$ & $1 \sim 4$ & Nothing & & $<3$ & $4 \sim 5$ & $>6$ & Other \\
\hline $\begin{array}{l}\text { Gyunggi } \\
\text { (No., \%) }\end{array}$ & $\begin{array}{c}3 \\
(27.3)\end{array}$ & $\begin{array}{c}7 \\
(63.6) \\
\end{array}$ & $\begin{array}{c}1 \\
(9.1) \\
\end{array}$ & $\begin{array}{c}23 \\
- \\
\end{array}$ & $7.33 \pm 6.0^{1)}$ & $\begin{array}{c}9 \\
(81.8) \\
\end{array}$ & $\begin{array}{c}1 \\
(9.1) \\
\end{array}$ & $\begin{array}{c}0 \\
(0.0) \\
\end{array}$ & $\begin{array}{c}1 \\
(9.1) \\
\end{array}$ \\
\hline $\begin{array}{c}\text { Chungnam } \\
\text { (No., \%) }\end{array}$ & $\begin{array}{c}3 \\
(27.3)\end{array}$ & $\begin{array}{c}7 \\
(63.6) \\
\end{array}$ & $\begin{array}{c}1 \\
(9.1) \\
\end{array}$ & $\begin{array}{l}22 \\
- \\
\end{array}$ & $6.59 \pm 5.29$ & $\begin{array}{c}9 \\
(81.8) \\
\end{array}$ & $\begin{array}{c}0 \\
(0.0)\end{array}$ & $\begin{array}{c}1 \\
(9.1) \\
\end{array}$ & $\begin{array}{c}1 \\
(9.1)\end{array}$ \\
\hline $\begin{array}{c}\text { Total, } \\
\text { (No., \%) }\end{array}$ & $\begin{array}{c}6 \\
(27.3) \\
\end{array}$ & $\begin{array}{c}14 \\
(63.6) \\
\end{array}$ & $\begin{array}{c}2 \\
(9.1) \\
\end{array}$ & $\begin{array}{l}45 \\
- \\
\end{array}$ & $6.93 \pm 5.47$ & $\begin{array}{c}18 \\
(81.8) \\
\end{array}$ & $\begin{array}{c}1 \\
(4.6) \\
\end{array}$ & $\begin{array}{c}1 \\
(4.6) \\
\end{array}$ & $\begin{array}{c}2 \\
(9.1) \\
\end{array}$ \\
\hline
\end{tabular}


상 이용한다가 $4.6 \%$, 기타가 $9.1 \%$ 로 나타났다. 대부분의 농가가 냉동초유를 3 개월 이내에 사용하고 있는 것으로 나타났으며, 조사지역간의 차이는 나타나지 않았으며 냉 동초유의 저장량과 이용기간은 적절한 것으로 분석되었다.

\section{8. 건유우 관리}

임신우의 건유 관리를 통한 초유의 품질향상 방안을 도 출하기 위해 건유연고 사용에 대한 조사결과를 Table 8에 나타내었다. 건유시 사용하는 건유연고는 주로 dicloxacillin 계열의 건유 연고를 사용하는 농가가 $18.5 \%$, cephalonium 계열의 건유연고를 사용한다가 $40.3 \%$, 기타 건유연고를 사용한다가 $39.8 \%$, 건유연고를 사용하지 않는다가 $3.0 \%$ 로 나타나, $97 \%$ 의 농가에서 건유연고를 사용하고 있는 것으 로 나타났다. 조사지역간에 사용하고 있는 건유연고의 종 류는 경기지역이 cephalonium 계열의 건유연고를 유의적으 로 많이 사용하고 있는 것으로 나타났다. 건유연고의 사 용회수에 대한 결과는 1회 사용한다가 $72.7 \%$ 로 가장 높았 고, 2회 사용한다가 $21.2 \%, 3$ 회 이상 사용한다가 $6.1 \%$ 를 차지하고 있는 것으로 조사되어 경기지역과 충남지역간의 건유연고 사용회수를 분석한 결과 충남지역이 2회 이상 사용한다는 농가가 $38.7 \%$ 로 유의적으로 높게 나타났다. 경기지역에서만 3회 이상 사용하는 4개의 농가가 확인 되 었는데 초유의 자원화를 위해서는 건유연고의 사용회수를 줄여야 할 것으로 판단된다.

Andrew (2001)는 초유 내 잔류 항생물질 검사의 특이성 에 관한 연구를 위하여 분만 전 30 일 이전에 항생제를 투 여하지 않은 홀스타인 젖소 초유 (1 3회 착유)와 전이초 유 (4 7회 착유)를 조사한 결과 초유에서 $0.16 ~ 0.88$ 이었고 전이초유에서는 $0.60 ~ 1.00$ 이라고 하여 잔류항생물질의 초 유로의 이행에 대해 보고한 바 있는데, 경기지역의 경우 $47.2 \%$ 가 장기 약효지속 건유연고를 사용하고 있는 것으로 나타나 초유의 자원화를 위해서는 건유연고 사용시 주의 해야 될 것으로 생각된다.
Oliver 등 (1984)은 건유우의 항생제 사용에 따른 초유 내 잔류연구를 위해 Delvo test 결과 186시료 중 4개 시료 가 Delvo test에서 양성을 나타내었으며, 대조군 48시료는 모두 음성으로 나타났다. 또한 건유시 $96 \%$ 이상이 건유연 고를 사용하고 있었으나 초유에 있어 중요한 문제는 아니 라고 하였다. 국내의 경우 $97 \%$ 이상의 농가에서 건유시 건유연고를 사용하고 있으며, 건유연고를 2회 이상 사용 한다는 농가가 $27.3 \%$ 로 많은 것으로 나타났다. 건유연고 의 부적절한 사용에 의해 초유 내 잔류항생물질의 잔류를 초래할 수 있을 것으로 생각되어 건유연고 사용법 준수가 필요한 것으로 나타났다.

\section{9. 건유연고 선발 및 사용방법}

낙농가에서 건유시 사용하고 있는 건유연고의 선택 이 유와 건유방법에 관한 결과를 Table 9에 나타내었다. 건유 연고의 선택이유는 약효지속기간이 길어서가 $48.5 \%$ 로 가 장 많이 응답했으며, 감수성 검사결과에 따라 건유연고를 선택한다가 $9.1 \%$ 로 나타났으며, 관행적으로 사용하기 때 문이 $34.9 \%$ 로 나타났으며, 조사 지역간의 차이는 없었다. 건유시에 건유연고의 사용방법에 있어서는 건유연고만 사 용한다가 $68.8 \%$, 유방염 연고만 사용한다가 $3.1 \%$, 건유연 고와 유방염 연고를 같이 사용한다가 $25.0 \%$, 기타가 $3.1 \%$ 인 것으로 조사되었다. Oliver 등 (1984)이 건유시에 $96 \%$ 이상이 건유연고를 사용하고 있었으나 초유에 있어 중요 한 문제는 아니라고 한 결과와 비교할 때 감수성 검사에 따른 건유연고를 선택하는 농가가 적고 약효지속시간 위 주로 선택하고 있어 건유연고의 올바른 사용방법에 대한 검증이 필요한 것으로 나타났다. 초유의 자원화를 통한 이용성을 향상시키기 위해서는 건유시 약효지속기간과 관 행적으로 사용하고 있는 건유연고의 사용방법을 지양하고, 감수성 검사결과에 따라 건유연고를 선택하여 사용하도록 하여 건유우 관리에 주의를 기울여야 할 것으로 나타났다.

Table 8. Management and use of medicines for dry off

\begin{tabular}{|c|c|c|c|c|c|c|c|}
\hline \multirow{2}{*}{ Items } & \multicolumn{4}{|c|}{ Kinds of medicine ${ }^{1)}$} & \multicolumn{3}{|c|}{$\begin{array}{c}\text { Frequency of use } \\
\text { (times) }\end{array}$} \\
\hline & $\mathrm{DC}$ & $\mathrm{CP}$ & Other & Not use & 1 & 2 & $\geq 3$ \\
\hline $\begin{array}{l}\text { Gyunggi } \\
\text { (No., \%) }\end{array}$ & $\begin{array}{c}3 \\
(8.3) \\
\end{array}$ & $\begin{array}{c}17 \\
(47.2)\end{array}$ & $\begin{array}{c}14 \\
(38.9) \\
\end{array}$ & $\begin{array}{c}2 \\
(5.6) \\
\end{array}$ & $\begin{array}{c}29 \\
(82.9) \\
\end{array}$ & $\begin{array}{c}2 \\
(5.7) \\
\end{array}$ & $\begin{array}{c}4 \\
(11.5) \\
\end{array}$ \\
\hline $\begin{array}{l}\text { Chungnam } \\
\text { (No., \%) }\end{array}$ & $\begin{array}{c}9 \\
(29.0)\end{array}$ & $\begin{array}{c}10 \\
(32.3) \\
\end{array}$ & $\begin{array}{c}12 \\
(38.7)\end{array}$ & $\begin{array}{c}0 \\
(0.0) \\
\end{array}$ & $\begin{array}{c}19 \\
(61.3) \\
\end{array}$ & $\begin{array}{c}12 \\
(38.7) \\
\end{array}$ & $\begin{array}{c}0 \\
(0.0)\end{array}$ \\
\hline $\begin{array}{c}\text { Total, } \\
\text { (No., \%) }\end{array}$ & $\begin{array}{c}12 \\
(18.5) \\
\end{array}$ & $\begin{array}{c}27 \\
(40.3)\end{array}$ & $\begin{array}{c}26 \\
(38.8) \\
\end{array}$ & $\begin{array}{c}2 \\
(3.0) \\
\end{array}$ & $\begin{array}{c}48 \\
(72.7) \\
\end{array}$ & $\begin{array}{c}14 \\
(21.2)\end{array}$ & $\begin{array}{c}4 \\
(6.1)\end{array}$ \\
\hline$x^{2}$ & \multicolumn{4}{|c|}{6.640} & \multicolumn{3}{|c|}{$13.032 * *$} \\
\hline
\end{tabular}

\footnotetext{
1) DC : dicloxacillin, CP : cephalonium.

* : Significant at 5\% probability levels.

** : Significant at $1 \%$ probability levels.
} 
Table 9. Reasons of selection and utilization method of drying off medicines

\begin{tabular}{|c|c|c|c|c|c|c|c|c|}
\hline \multirow{2}{*}{ Items } & \multicolumn{4}{|c|}{ Reasons of selection ${ }^{1)}$} & \multicolumn{4}{|c|}{ Using method of drying off medicine ${ }^{2)}$} \\
\hline & LE & ST & TU & Other & DS & $\mathrm{MO}$ & $\mathrm{DM}$ & Other \\
\hline $\begin{array}{l}\text { Gyunggi } \\
\text { (No., \%) }\end{array}$ & $\begin{array}{c}16 \\
(44.4)\end{array}$ & $\begin{array}{c}4 \\
(11.1) \\
\end{array}$ & $\begin{array}{c}11 \\
(30.6)\end{array}$ & $\begin{array}{c}3 \\
(8.3) \\
\end{array}$ & $\begin{array}{c}25 \\
(75.7) \\
\end{array}$ & $\begin{array}{c}0 \\
(0.0) \\
\end{array}$ & $\begin{array}{c}7 \\
(21.2)\end{array}$ & $\begin{array}{c}1 \\
(3.0) \\
\end{array}$ \\
\hline $\begin{array}{c}\text { Chungnam } \\
\text { (No., \%) }\end{array}$ & $\begin{array}{c}16 \\
(51.6)\end{array}$ & $\begin{array}{c}2 \\
(6.5)\end{array}$ & $\begin{array}{c}12 \\
(38.7)\end{array}$ & $\begin{array}{c}0 \\
(0.0)\end{array}$ & $\begin{array}{c}19 \\
(61.3)\end{array}$ & $\begin{array}{c}2 \\
(6.5) \\
\end{array}$ & $\begin{array}{c}9 \\
(29.0)\end{array}$ & $\begin{array}{c}1 \\
(3.2) \\
\end{array}$ \\
\hline $\begin{array}{c}\text { Total, } \\
\text { (No., \%) }\end{array}$ & $\begin{array}{c}32 \\
(48.5)\end{array}$ & $\begin{array}{c}6 \\
(9.1)\end{array}$ & $\begin{array}{c}23 \\
(34.9)\end{array}$ & $\begin{array}{c}3 \\
(4.5)\end{array}$ & $\begin{array}{c}44 \\
(68.8)\end{array}$ & $\begin{array}{c}2 \\
(3.1)\end{array}$ & $\begin{array}{c}16 \\
(25.0)\end{array}$ & $\begin{array}{c}2 \\
(3.1)\end{array}$ \\
\hline
\end{tabular}

1) LE : lasting effects, ST : sensitivity test result, TU : traditional use.

2) DS : dry off medicine only, MO : mastitis ointment only, DM : dry off medicine + mastitis ointment.

\section{0. 분만전후 항생제 사용}

초유의 품질향상을 위하여 분만 전후의 항생제 사용현 황을 조사한 결과를 Table 10에 표시하였다. 분만 전후 초 유 생산시기에 항생제를 사용하는 경우가 있는가에 대하 여, 사용하지 않는다가 $20.9 \%$, 가끔 있다가 $58.2 \%$, 자주 있다가 $6.0 \%$, 분만할 때마다 사용한다가 $14.9 \%$ 로 나타났 으며, 경기지역과 충남지역간에는 분만 전후에 항생제 사 용에 있어 유의적인 차이점이 있는 것으로 조사되었다. 특히 경기지역의 농가 11 곳은 항생제를 전혀 사용하지 않 았는데, 다른 농가에서도 초유의 자원화를 위해서는 항생 제 사용 자제는 반드시 이행되어져야 할 것이라 판단된다. 분만 전후에 항생제를 사용하게 되는 가장 큰 이유는 난 산 때문이 $5.7 \%$, 제왕절개 등의 수술 때문이 $11.3 \%$, 후산 정체로 인해서가 $3.8 \%$, 염증예방을 위해서가 $67.9 \%$ 로 나 타났으며, 기타가 $11.3 \%$ 로 나타났다. 그리고 분만 전후에 항생제의 투약기간은 평균 $2.24 \pm 1.5$ 일인 것으로 조사되었 다. 조사지역간의 유의적인 차이는 나타나지 않았다. 분만 전후에 항생제 사용에 있어 자주 또는 매번 사용한다가 $20.9 \%$ 로 나타났는데 이는 초유 급여기간에 납유를 하지
않음에 따른 농가 관행으로 생각되며 분만에 따른 산도의 염증예방을 위해 많은 농가에서 분만 전후에 항생제를 사 용하고 있어 초유 내 항생물질 잔류가 문제가 되는 것으 로 나타났다.

\section{1. 초유의 자원화}

Table 11은 남는 초유의 자원화와 관련하여 판매 희망 여부와 적정 가격에 대한 의견을 질문한 결과를 나타내었 다. 초유를 구입하기 원하는 대상자가 있다면 판매하겠는 가에 대한 질문에 판매하겠다가 $58.2 \%$, 판매하지 않겠다 가 $41.8 \%$ 로 나타났으며, 조사 지역간의 차이는 나타나지 않았다. 적절한 초유의 판매 가격에 대해서 원유의 가격 과 같은 수준이 $43.6 \%$, 두 배 수준이 $46.2 \%, 3$ 배 수준이 $10.3 \%$ 로 조사되었으며, 조사지역간의 차이는 없었다. 초유 를 자원화하기 위하여 집유할 경우 농가에서는 건유우 관 리에 건유연고의 사용과 분만 전후의 항생제 사용에 대한 적절한 관리를 통해 초유의 품질 향상이 필요할 것으로 사료된다.

Table 10. Use of antibiotics before and after parturition

\begin{tabular}{|c|c|c|c|c|c|c|c|c|c|c|}
\hline \multirow{2}{*}{ Items } & \multicolumn{4}{|c|}{ Frequency of antibiotics use ${ }^{1)}$} & \multicolumn{5}{|c|}{ Reason for using antibiotics ${ }^{2)}$} & \multirow{2}{*}{$\begin{array}{c}\text { Medical cure } \\
\text { period } \\
\text { (days) }\end{array}$} \\
\hline & None & $\mathrm{OU}$ & FU & $\mathrm{EU}$ & BT & $\mathrm{SG}$ & $\mathrm{RP}$ & PI & Other & \\
\hline $\begin{array}{l}\text { Gyunggi } \\
\text { (No., \%) }\end{array}$ & $\begin{array}{c}11 \\
(30.6)\end{array}$ & $\begin{array}{c}22 \\
(61.1)\end{array}$ & $\begin{array}{c}1 \\
(2.8)\end{array}$ & $\begin{array}{c}2 \\
(5.6)\end{array}$ & $\begin{array}{c}2 \\
(8.0)\end{array}$ & $\begin{array}{c}4 \\
(16.0)\end{array}$ & $\begin{array}{c}2 \\
(8.0)\end{array}$ & $\begin{array}{c}13 \\
(52.0)\end{array}$ & $\begin{array}{c}4 \\
(16.6)\end{array}$ & $2.75 \pm 1.8^{3)}$ \\
\hline $\begin{array}{c}\text { Chungnam } \\
\text { (No., \%) }\end{array}$ & $\begin{array}{c}3 \\
(9.7) \\
\end{array}$ & $\begin{array}{c}17 \\
(54.8) \\
\end{array}$ & $\begin{array}{c}3 \\
(9.7)\end{array}$ & $\begin{array}{c}8 \\
(25.8)\end{array}$ & $\begin{array}{c}1 \\
(3.6)\end{array}$ & $\begin{array}{c}2 \\
(7.1)\end{array}$ & $\begin{array}{c}0 \\
(0.0)\end{array}$ & $\begin{array}{c}23 \\
(82.1)\end{array}$ & $\begin{array}{c}2 \\
(7.1)\end{array}$ & $1.77 \pm 0.9$ \\
\hline $\begin{array}{c}\text { Total, } \\
\text { (No., \%) }\end{array}$ & $\begin{array}{c}14 \\
(20.9)\end{array}$ & $\begin{array}{c}39 \\
(58.2)\end{array}$ & $\begin{array}{c}4 \\
(6.0)\end{array}$ & $\begin{array}{c}10 \\
(14.9)\end{array}$ & $\begin{array}{c}3 \\
(5.7)\end{array}$ & $\begin{array}{c}6 \\
(11.3)\end{array}$ & $\begin{array}{c}2 \\
(3.8)\end{array}$ & $\begin{array}{c}36 \\
(67.9)\end{array}$ & $\begin{array}{c}6 \\
(11.3)\end{array}$ & $2.24 \pm 1.5$ \\
\hline$x^{2}$ & & & & & & & 6.295 & & & \\
\hline
\end{tabular}

\footnotetext{
1) $\mathrm{OU}$ : often use, FU : frequently use, EU : every times use.

2) $\mathrm{BT}$ : birth trouble, SG : surgery, RP : retained placenta, PI : prevent inflammation.

3) Mean \pm SD.

* : Significant at 5\% probability levels.
} 
Table 11. Opinions and price for the marketing of surplus colostrum

\begin{tabular}{|c|c|c|c|c|c|}
\hline \multirow{2}{*}{ Items } & \multicolumn{2}{|c|}{ Sell of colostrum } & \multicolumn{3}{|c|}{ Proper price of colostrum } \\
\hline & Would sell & Won't sell & Same as raw milk & Double & Triple \\
\hline $\begin{array}{l}\text { Gyunggi } \\
\text { (No., \%) }\end{array}$ & $\begin{array}{c}23 \\
(63.9)\end{array}$ & $\begin{array}{c}13 \\
(36.1)\end{array}$ & $\begin{array}{c}9 \\
(39.1)\end{array}$ & $\begin{array}{c}11 \\
(47.8)\end{array}$ & $\begin{array}{c}3 \\
(13.1)\end{array}$ \\
\hline $\begin{array}{c}\text { Chungnam } \\
\text { (No., \%) }\end{array}$ & $\begin{array}{c}16 \\
(51.6)\end{array}$ & $\begin{array}{c}15 \\
(43.4)\end{array}$ & $\begin{array}{c}8 \\
(50.0) \\
\end{array}$ & $\begin{array}{c}7 \\
(43.7) \\
\end{array}$ & $\begin{array}{c}1 \\
(6.3) \\
\end{array}$ \\
\hline $\begin{array}{c}\text { Total, } \\
\text { (No., \%) }\end{array}$ & $\begin{array}{c}39 \\
(58.2)\end{array}$ & $\begin{array}{c}28 \\
(41.8)\end{array}$ & $\begin{array}{c}17 \\
(43.6)\end{array}$ & $\begin{array}{c}18 \\
(46.2)\end{array}$ & $\begin{array}{c}4 \\
(10.3)\end{array}$ \\
\hline
\end{tabular}

IV. 요 약

초유는 신생 송아지에게 완전식품으로 제공된다. 반추 동물에서 초유는 송아지에게 처음 제공되는 후천적 면역 물질의 유일한 공급원이다. 따라서 초유는 반추동물의 숙 주방어에서 중요한 역할을 한다. 소의 초유는 신생 송아 지에게 처음 24시간 동안 수동 면역물질을 공급하고, 일 반적으로 생후 처음 3 일 동안 공급된다. 초유는 저장 후 사용을 위해 냉각, 냉동 또는 대기온도에서 발효 또는 화 학처리에 의해 보관할 수 있다. 초유관리 조사는 경기와 충남지역에 있는 67 개 낙농가로부터 자료 수집을 통하여 조사하였다. 분만 후 5일 동안 생산한 초유의 총 생산량 은 평균 $80.4 \mathrm{~kg}$ 이었고, 송아지에게 급여한 포유량은 평균 $20.9 \mathrm{~kg}$ 이었다. 조사결과에 따르면, 남는 초유의 처리방법 은 그냥 버린다가 $17.9 \%$, 다른 송아지 포유용으로 이용한 다가 $37.3 \%$, 저장 이용한다가 $22.4 \%$, 다른 가축에게 준다 가 $20.9 \%$, 기타방법으로 처리한다가 $1.5 \%$ 로 확인되었다. 초유의 품질향상을 위해서는 분만전후의 항생제 사용자제 와 건유연고의 올바른 선택, 착유 초기동안 착유량을 증 대해야 할 것으로 나타났다.

\section{$\mathrm{V}$. 인 용 문 헌}

1. Andrew, S. M. 2001. Effect of composition of colostrum and transition milk from Holstein heifers on specificity rates of antibiotic residue tests. J. Dairy Sci. 84(1):100-106.

2. Butler, J. E. 1971. Characteristics of bovine immunoglobulins and related molecules. review of bovine immunoglobulins. J. Dairy Sci. 54(9):1315-1316.

3. Butler, J. E. 1986. Biochemistry and biology of ruminant Immunoglobulin. Prog. Vet. Microbiol. Immunol. 2:1-53.

4. Drevjany, L. A., Irvine, O. R. and Hooper, G. S. 1975. Attempt to improve storage life, palatability, uniformity and nutritive value of fermented colostrum and its utilization in raising replacement calves. Paper presented at the Annual Meeting of the Eastern Branch of the Can. Soc. of Anim. Sci., Kemptville, Ontario, May 25-27, 1975.

5. Hadorn, U., Hammon, H., Bruckmaier, R. M. and Blum, J. W. 1997. Delaying colostrum intake by one day has important effects on metabolic traits and on gastrointestinal and metabolic hormones in neonatal calves. J. Nutr. 127(10):20112023.

6. Heinrichs, A. J., Wells, S. J. and Losinger, W. C. 1995. A study of the use of milk replacers for dairy calves in the United States. J. Dairy Sci. 78(12):2831-2837.

7. Huber, J. T. 1974. Nutrient needs of the preruminant calf. 7th Annu. Conv. Amer. Ass. Bovine Pract. Proceeding. 128-132.

8. Kirihara, O. 1990. Separation and utilization of bovine immunoglobulin. Fapanese J. Dairy and Food Sci. 39(6):A391-395.

9. Lori C. Pritcette, Clive C. Gay, Thomas E. Besser and Dale D. Hancock. 1991. Management and Production Factors Influencing Immunoglobulin G1 Concentration in Colostrum from Holstein Cows. J. Dairy Sci. 74:2336-2341.

10. Oliver, S. P., Duby, R. T., Prange, R. W. and Tritschler, J. P. 2nd. 1984. Residues in colostrum following antibiotic dry cow therapy. J. Dairy Sci. 67(12):3081-3084.

11. Pritchett, L. C., Gay, C. C., Besser, T. E. and Hancock, D. D. 1991. Management and production factors influencing immunoglbulin G1 concentration in colostrum from Holstein cows. J. Dairy Sci. 74:2336-2341.

12. Spicer, H. M. Goonewardene, L. A., McNeil, A. O. and Slack, W. L. 1994. Alberta dairy farm survey response. J. Dairy Sci. 77:3460-3472.

13. Stabel, J. R. 2001. On-farm batch pasteurization destroys Mycobacterium paratuberculosis in waste milk. J. Dairy Sci. 84(2):524-527.

14. Stott, G. H., Fleenor, W. A. and Kleese, W. K. 1981. Colostral immunoglobulin concentration in two fractions of first milking postpartum and five additional milkings. J. Dairy Sci. 64(3):459-465.

15. Weaver, D. M., Tyler, J. W., VanMetre, D. C., Hostetler D. E. and Barrington, G. M. 2000. Passive transfer of colostral immunoglobulins in calves. J. Vet. Intern. Med. 14(6):569-577.

16. Yu, Y., Stone, J. B. and Wilson, M. R. 1976. Fermented bovine colostrum for Holstein replacement calf rearing. J. Dairy Sci. 59(5):936-943.

(접수일자 : 2009. 3. 10. / 수정일자 : 2009. 3. 31. /

채택일자 : 2009. 4. 17.) 